April 2019 Volume 2 No 2

\title{
IMPLEMENTATION OF SWOT ANALYSIS: CASE STUDY OF CROT-DE BUSINESS (CROCODILE TONGUE POMADE)
}

\section{PENERAPAN ANALISIS SWOT: STUDI KASUS USAHA MAHASISWA CROT-DE (CROCODILE TONGUE POMADE)}

\author{
Muhammad Alvinza Chairyan ${ }^{1}$, Ari Zulfi Kharisma ${ }^{1}$, \\ Muhammad Hanafi Lubis ${ }^{1}$,Dhea Octa Yolanda ${ }^{1}$, Suhelni $^{1}$ \\ ${ }^{1)}$ Program Studi Agribisnis, Universitas Muhammadiyah Sumatera Utara \\ Jl. Kapten Mukhtar Basri No. 3A Medan \\ dheaoctayolanda@gmail.com
}

\begin{abstract}
The term pomade comes from French, which is pommade, which means 'ointment'. The use of pomades dates back to the 1800s. During this century, and the main ingredients used in making pomade were bear fat. Pomade is a male cosmetic product that is in great demand, especially teenagers. Men's hairstyles are various, but the most favorite hairstyles are undercut and pompadour, this hairstyle will be more beautiful when using pomade. However, pomade on the market contains chemicals that can cause side effects for hair, and also have a price that is quite draining. Therefore, we brought up a new innovation herbal product, namely CROT-DE (Crocodile Tongue Pomade). Pomade CROT-DE products are prepared from basic ingredients, namely Aloe Vera. Aloe vera is processed into a beauty product, which is commonly used by men as a cosmetic product for hair that is used so that their hair is smooth, cool and confident. The research method used was using a qualitative approach. Qualitative research is research that intends to understand the phenomenon of what is experienced by the subject of research such as behavior, perception, motivation, actions and others holistically and by way of description in the form of words and language, in a special context that is natural and with utilizing various natural methods. From the definition above, it can be concluded that the researcher is trying to understand the phenomenon experienced by the subject, be it behavior, perception, motivation, etc. This business has a huge opportunity because many pomade products on the market still use chemicals. Of course this refers to the creation of CROT-DE pomade products with natural ingredients from aloe vera. Therefore, in this article I will discuss the SWOT analysis. SWOT analysis is a strategy in evaluating strengths, weaknesses, opportunities, and threats which can be applied generally to business activities. SWOT analysis is a strategic planning method consisting of aspects of the product (strength), product Weaknesses, product opportunities, and product threats. First, strength is the raw materials needed in making Pomade products that are very easy to obtain. Second, the weakness strategy (weakness) is that the pomade product is not widely known by the public. Third, the opportunity strategy is the absence of Pomade products that use natural ingredients. Fourth, the threat strategy is to have a fairly heavy competitor whose products are first known in the market.
\end{abstract}

Keywords : SWOT analysis, Pomade, CROT-DE

\begin{abstract}
Abstrak
Istilah pomade berasal dari Bahasa Perancis, yaitu pommade, yang artinya 'salep'. Pemakaian pomade bermula sejak tahun 1800-an. Selama abad ini, dan bahan utama yang digunakan dalam pembuatan pomade adalah lemak beruang. Pomade merupakan produk kosmetik pria yang sangat diminati terutama para remaja. Gaya rambut pria berbagai macam, namun gaya rambut paling favorit yaitu undercut dan pompadour, gaya rambut ini akan lebih indah dipandang jika menggunakan pomade. Namun, pomade yang beredar di pasaran mengandung bahan-bahan kimia yang dapat menimbulkan efek samping bagi rambut, dan juga memiliki harga yang cukup menguras kantong. Maka dari itu, kami memunculkan produk berupa pomade herbal inovasi baru, yaitu CROT-DE (Crocodile Tongue Pomade). Produk Pomade CROT-DE diolah dari bahan dasar yaitu Lidah Buaya. Lidah Buaya diolah menjadi produk
\end{abstract}




\section{Muhammad Alvinza Chairyan, Ari Zulfi Kharisma, Muhammad Hanafi Lubis, Dhea Octa Yolanda, Suhelni}

kecantikan, yang biasa digunakan para kaum pria sebagai produk kosmetik untuk rambut yang digunakan agar rambutnya klimis, tampil keren dan percaya diri. Metode penelitian yang digunakanya itu menggunakan pendekatan kualitatif. Penelitian kualitatif adalah penelitian yang bermaksud untuk memahami fenomena tentang apa yang dialami oleh subjek penelitian misalnya perilaku, persepsi, motivasi, tindakan dan lain-lain secara holistik dan dengan cara deskripsi dalam bentuk kata-kata dan bahasa, pada suatu konteks khusus yang alamiah dan dengan memanfaatkan berbagai metode alamiah. Dari pengertian di atas, maka dapat disimpulkan bahwa peneliti berusaha untuk memahami fenomena yang dialami oleh subjek baik itu perilaku, persepsi, motivasi, dan lain-lain.. Usaha ini memiliki peluang yang sangat besar karena banyak produk pomade yang dipasaran masih menggunakan bahan-bahan kimia. Tentu hal ini mengacu pada terciptanya produk pomade CROT-DE dengan berbahan dasar alami dari lidah buaya. Maka dari itu, di artikel ini akan membahas analisis SWOT. Analisis SWOT adalah sebuah strategi dalam mengevaluasi kekuatan, kelemahan, peluang, serta ancaman yang hal ini dapat diterapkan pada umunya untuk kegiatan bisnis. Analisis SWOT adalah metode perencanaan strategis yang terdiri dari aspek Strenght (kekuatan) produk, Weaknesses (kelemahan) produk, Opportunities (peluang) produk, dan Threats (ancaman) produk. Pertama, kekuatan (strength) adalah bahan-bahan baku yang dibutuhkan dalam pembuatan produk pomade ini sangat mudah di dapat. Kedua, pada strategi kelemahan (weakness) adalah produk pomade ini belum banyak diketahui oleh masyarakat. Ketiga, pada strategi peluang (opportuninities) adalah belum adanya produk pomade yang menggunakan bahan-bahan alami. Keempat, pada strategi ancaman (threats) adalah memiliki pesaing yang cukup berat yang produknya lebih dulu dikenal dipasaran.

Kata Kunci : Analisis SWOT, Pomade, CROT-DE

\section{A. PENDAhuluan}

Jauh sebelumnya, kelahiran pomade dapat ditelusuri. Istilah pomade berasal dari Bahasa Perancis, yaitu pommade, yang artinya 'salep'. Pomade modern saat ini, yang telah beredar dipasaran mengandung bahan-bahan kimia yang dapat merusak rambut. Pemakaian pomade bermula sejak tahun 1800-an. Selama abad ini, dan bahan utama yang digunakan dalam pembuatan pomade adalah lemak beruang. Di awal abad ke-20, bahan-bahan lainnya seperti petroleum jelly, lilin lebah, dan lemak babi menggantikan lemak beruang. Untuk menciptakan model rambut klimis dan berbagai model gaya rambut pada laki-laki, beragam-ragam produk dan merek pomade yang dipasarkan. Di pertengahan abad ke-20 tren pomade begitu populer, sangat banyak diminati oleh kaum pria.

Contoh paling umum gaya rambut yang cocok menggunakan pomade adalah gaya rambut pompadour, yaitu rambut tersapu tinggi ke atas, namun rambut di bagian samping tipis. Selebriti yang memakai model rambut ini dan mempopulerkannya adalah Elvis Presley. Model rambut lain yang cocok menggunakan pomade adalah gaya rambut quiff. Gaya rambut quiff ini sekilas kalau dilihat bentuknya mirip banget sama gaya rambut pompadour. Bedanya terletak pada cara menyisir rambut di bagian atas. Gaya rambut Pompadour menyisir rambut jambul rapih ke samping, sedangkan model rambut quiff menyisir rambut jambul kearah depan hingga terlihat seperti messy hair. Selebritis Hollywood yang sering terlihat tampil memakai gaya rambut ini adalah Robert Pattinson, actor yang populer karena film yang dibintanginya, Twilight. Berlimpahnya laki-laki memakai pomade melahirkan sebutan khusus bagi mereka, yaitu 'greasers'.

Pada masa itu, laki-laki memakai pomade yang sangat banyak untuk menahan rambut tidak berubah bentuk. Dalam perkembangannya, terutama dalam zaman millennial saat ini, laki-laki memakai pomade untuk bergaya.

Pomade dipakai agar rambut mudah ditata dan tidak mudah berantakan. Pomade juga seringkali dipakai untuk membuat beberapa gaya rambut klasik. Dan pomade juga digunakan untuk mengesankan tampilan basah pada rambut, meskipun kenyataannya rambut tetap kering.

Ratusan produk pomade berbeda bertebaran di pasar saat ini. Masing-masing memiliki jumlah kadar minyak yang berbeda, biasanya petroleum jelly, lilin lebah, dan fragrance untuk memberikan aroma. Laki-laki yang ingin rambutnya kaku lebih lama, disarankan memakai produk dengan kandungan lilin yang lebih tinggi.

Namun jika hendak bergaya dengan rambut bersinar dan tidak terlalu kaku, produk pomade yang mengandung minyak atau lemak lebih banyak dengan lilin sedikit adalah yang terbaik. Berbagai pilihan pomade banyak ditawarkan sehingga memilih pomade untuk 


\section{IMPLEMENTATION OF SWOT ANALYSIS: CASE STUDY OF CROT-DE BUSINESS}

rambut pun sangat tergantung pada pilihan gaya pribadi masing-masing lelaki. (Gita, 2014) ${ }^{1}$

Seiring dengan perkembangan dan perubahan zaman, saat ini para kaum pria sudah memiliki kepedulian terhadap penampilan yang sama besarnya seperti para kaum wanita. Karena itulah mulai banyak bermunculan brand-brand yang menjual aneka keperluan fashion dan kosmetik untuk kaum pria.

Selain gaya berbusana, para cowok ini juga sangat concern pada gaya rambut. Karena gaya rambut juga menunjang penampilan terlihat lebih menarik. Banyak sekali aneka gaya rambut baru yang bermunculan, dan dipopulerkan oleh para selebritis dan para pemain sepakbola terkenal dunia. Dari sekian banyak gaya rambut, inilah 7 gaya rambut yang populer banget di kalangan para kaum pria :

\section{Gaya Undercut}

Salah satu selebritis yang mempopulerkan gaya rambut ini adalah Brad Pitt. Gaya rambut ini cocok dipakai oleh semua kaum pria, potongan rambut ini dibagian sisinya di buat pendek dan panjang di bagian atas rambut. Ciri khas gaya undercut tidak memiliki degradasi, bagian bawahnya dicukur dengan ukuran sampa panjang.

\section{Gaya Pompadour}

Model rambut Pompadour adalah model rambut pria potongannya tipis di bagian samping, namun tinggi dibagian atas. Ciri-ciri model rambut ini yang paling mudah diingat adalah bagian atasnya yang berjambul. Untuk membuat model Pompadour ini bertahan lama, jangan lupa untuk memakai pomade saat ke luar rumah

\section{Gaya Quiff}

Gaya rambut quiff ini sekilas kalau dilihat bentuknya mirip banget sama gaya rambut pompadour. Bedanya terletak pada cara menyisir rambut di bagian atas. Gaya rambut Pompadour menyisir rambut jambul rapih ke samping, sedangkan model rambut quiff menyisir rambut jambul kearah depan hingga terlihat seperti messy hair. Selebritis Hollywood yang sering terlihat tampil memakai gaya rambut ini adalah Robert Pattinson, aktor yang populer karena film yang dibintanginya, Twilight.

\section{Gaya Fringe}

Gaya Fringe ini adalah gaya rambut berponi yang populer banget di negara-negara Asia seperti Korea, Jepang, dan Cina. Salah satu oppa Korea yang konsisten memakai gaya rambut ini adalah Lee Min Ho. Kalau kamu salah seorang Kpopers, pasti kamu sudah tidak asing dengan gaya rambut yang satu ini. Kalau untuk menata gaya rambut ini, tidak menggunakan pomade pun juga bisa.

\section{Gaya Slicked Back}

Salah satu selebritis Hollywood yang gemar memakai gaya rambut ini adalah Leonardo Di Caprio, aktor ternama Hollywood yang populer karena film yang dibintanginya, Titanic . Bahkan aktor Keanu Reeves di film The Matrix juga selalu memakai gaya rambut ini. Gaya Slicked Back ini klimis dan rapi banget, jadi cocok dipakai untuk menghadiri acara formal. Jangan lupa untuk selalu memakai pomade kalau kamu ingin memakai gaya ini.

\section{Gaya Man Bun}

Kalau lihat gaya rambut yang satu ini, pasti langsung ingat dengan sosok David Beckham karena Beckham lah maka gaya rambut ini begitu populer. Romeo Beckham, Jared Letto, Orlando Bloom hingga Justin Bieber juga pernah memakai gaya Man Bun ini. Gaya rambut ini menguncir rambut kebelakang.

\section{Gaya Buzz Cut}

Gaya rambut yang satu ini juga dikenal dengan nama crew cut atau military hair cut karena potongan rambutnya super pendek, dan sering dipakai oleh para tentara. Selebritis yang suka memakai gaya rambut yang satu ini adalah Nick Jonas, dan Zayn Malik.(Ayana, 2018) ${ }^{2}$

Pomade merupakan produk yang sangat diminati para kaum pria terutama para remaja masa kini dan rata-rata remaja pria menggunakan pomade agar rambutnya klimis, tampil keren dan percaya diri. Namun, pomade yang beredar di pasaran mengandung bahanbahan kimia yang dapat menimbulkan efek samping bagi rambut. Hasil 9 dari 10 orang yang telah kami wawancarai, mengatakan bahwa pomade yang mereka pakai menyebabkan rambut berketombe, rambut rontok, rambut menjadi kusam, dan sebagainya. Setelah ditelusuri, ternyata pomade yang banyak beredar dipasaran mengandung unsur-unsur kimia yang dapat menimbulkan efek samping bagi rambut. Beberapa contoh bahan-bahan kimia yang terdapat pada pomade yang telah beredar dipasaran, yaitu glycerol dan butyclene glycol. Maka dari itu, kami menghadirkan sebuah inovasi baru yang belum ada di pasar, yaitu CROT-DE (Crocodile Tongue Pomade) Inovasi Pomade Herbal Sebagai Pengganti Pomade Kimia Dengan Konsep 4 In 1. Inovasi yang kami buat ini yaitu pomade yang menggunakan bahan-bahan alami tanpa ada 
bahan-bahan kimia yang dapat merusak atau menimbulkan efek samping bagi rambut. Produk ini memiliki Konsep 4 In 1 yaitu mencegah/menghilangkan rambut berketombe, mencegah/menghilangkan rambut rontok, menghitamkan warna rambut, dan mempercepat pertumbuhan rambut. Bahan utama yang digunakan dalam pembuatan pomade CROT-DE yaitu lidah buaya. Dan didukung oleh bahanbahan lainnya, yaitu lilin lebah (beeswax), minyak zaitun, minyak kelapa, dan kulit jeruk. Bahan-bahan yang digunakan dalam pembuatan produk ini sangat mudah didapat di lingkungan sekitar sehingga akan mempercepat proses produksi dan dapat segera dipasarkan sehingga dapat dijangkau oleh masyarakat. Dengan hadirnya produk ini, maka akan menggantikan produk pomade yang sudah ada di pasar karena produk yang ada di pasar mengandung bahanbahan kimia yang dapat menimbulkan efek samping bagi rambut, sedangkan produk kami hadir dengan menggunakan bahan-bahan alami yang tidak akan merusak rambut. Analisis SWOT adalah identifikasi berbagai faktor secara sistematis untuk merumuskan strategi perusahaan. Analisis ini didasarkan pada logika yang dapat memaksimalkan kekuatan (Strength), dan peluang (Opportunities), namun secara bersamaan dapat meminimalkan kelemahan (Weakness) dan ancaman (Threats). Analisis SWOT telah menjadi salah satu alat yang berguna dalam dunia bisnis. Metode ini merupakan sebuah analisa yang cukup baik, efektif dan efisien serta sebagai alat yang cepat dan tepat dalam menemukan dan mengenali kemungkinan-kemungkinan yang berkaitan dengan inovasi baru dalam dunia bisnis. (Syamsudin Noor, 2014) ${ }^{3}$.

Analisis SWOT sangat dibutuhkan untuk memperlancar jalannya kegiatan usaha. Analisis SWOT dapat berupa penilaian menyeluruh yang dilakukan terhadap kekuatan, peluang, kelemahan dan ancaman suatu kegiatan yang akan dilakukan. Kekuatan dan peluang sangat diperlukan dalam kelancaran kegiatan usaha yang akan dijalankan. Selain itu, analisis SWOT juga membantu agar terhindar dari ancaman-ancaman yang akan diperoleh di saat kemudian.

Dengan melihat kekuatan yang dimiliki serta mengembangkan kekuatan tersebut dapat dipastikan bahwa perusahaan akan lebih maju dibanding pesaing yang ada. Demikian juga dengan kelemahan yang dimiliki harus diperbaiki agar perusahaan bisa tetap eksis $\left(\right.$ Tamara, 2016) ${ }^{4}$. Analsis SWOT digunakan untuk melihat kekuatan, kelemahan, peluang dan ancaman yang akan dihadapi oleh perusahaan. Dengan melihat kekuatan yang dimiliki serta mengembangkan kekuatan tersebut dapat dipastikan bahwa perusahaan akan lebih maju dibanding pesaing yang ada. Demikian juga dengan kelemahan yang dimiliki harus diperbaiki agar perusahaan bisa tetap eksis. Peluang yang ada harus dimanfaatkan sebaik-baiknya oleh perusahaan agar volume penjualan dapat meningkat. Dan ancaman yang akan dihadapi oleh perusahaan haruslah dihadapi dengan mengembangkan strategi pemasaran yang baik

(Angelica Tamara, 2017) ${ }^{5}$.

Berdasarkan hasil strategi analisis SWOT seperti yang telah diuraikan di bagian ini, bisnis pomade CROT-DE memiliki strategi-strategi analisis lingkungan internal dan eksternal yang telah diuraikan. Lingkungan tersebut dapat digunakan untuk mendapatkan peluang dan kekuatan yang dapat menghasilkan keuntungan dari bisnis yang akan berlangsung. Dari strategi dapat dianalisis pada aspek produk dan harga yang akan dihasilkan. Strategi-strategi sebagai dasar dalam menciptakan pemasaran yang efektif agar konsumen dapat mengenal dan tertarik hingga memiliki loyalitas terhadap produk.

Strengths (kekuatan) adalah kegiatan-kegiatan organisasi yang berjalan dengan baik atau sumber daya yang dapat dikendalikan. Weaknesses (kelemahan) adalah kegiatankegiatan organisasi yang tidak berjalan dengan baik atau sumber daya yang dibutuhkan oleh organisasi tetapi tidak dimiliki oleh organisasi, Analisis SWOT dalam Pengembangan Bisnis Opportunities (peluang / kesempatan) adalah faktor-faktor lingkungan luar yang positif. Threats (ancaman) adalah faktor-faktor lingkungan luar yang negatif (Istiqomah dan Irsad, 2017) ${ }^{6}$.

Strategi-strategi yang telah dirumuskan dari analisis SWOT adalah membuat produk yang akan dibuat (strategi SO), melakukan periklanan yang efektif melalui berbagai media sosial (strategi WO), menetapkan herga yang terjangkau dan ekonomis (strategi OT), dan meningkatkan program pemasaran untuk persaingan yang berkelanjutan (strategi WT).

\section{B. METODE PENELITIAN}

Dalam penelitian ini, peneliti menggunakan pendekatan kualitatif. Menurut (Moleong, 2011) ${ }^{7}$ Penelitian kualitatif adalah penelitian yang bermaksud untuk memahami 


\section{IMPLEMENTATION OF SWOT ANALYSIS: CASE STUDY OF CROT-DE BUSINESS}

fenomena tentang apa yang dialami oleh subjek penelitian misalnya perilaku, persepsi, motivasi, tindakan dan lain-lain secara holistik dan dengan cara deskripsi dalam bentuk kata-kata dan bahasa, pada suatu konteks khusus yang alamiah dan dengan memanfaatkan berbagai metode alamiah. Dari pengertian di atas, maka dapat disimpulkan bahwa peneliti berusaha untuk memahami fenomena yang dialami oleh subjek baik itu perilaku, persepsi, motivasi, dan lainlain. Sumber Data dari penelitian ini adalah data Primer yaitu jenis data berupa opini, sikap, pengalaman atau karakteristik dari seorang atau sekelompok orang yang menjadi subyek penelitian. Sumber data dari jenis data primer untuk penelitian adalah hasil wawancara secara langsung dengan pihak terkait yang menangani bagian yang bersangkutan dengan masalah yang akan diteliti peneliti. Data Sekunder adalah data yang diperoleh lewat pihak lain, tidak langsung diperoleh oleh peneliti dari subjek penelitiannya. Data sekunder ini disebut juga dengan data tangankedua. Data Sekunder biasanya berwujud data dokumentasi atau data laporan yang telah tersedia berupa data, bukti, dokumentasi atau catatan.

\section{HASIL DAN PEMBAHASAN}

Hasil dari penelitian ini adalah sebuah produk untuk dijadikan sebagai peluang bisnis mahasiswa yang dinamakan dengan Pomade CROT-DE. Produk Pomade CROT-DE diolah dari bahan dasar yaitu Lidah Buaya. Lidah Buaya diolah menjadi produk kecantikan, yang biasa digunakan para kaum pria sebagai produk kosmetik untuk rambut yang digunakan agar rambutnya klimis, tampil keren dan percaya diri. Usaha ini memiliki peluang yang sangat besar karena banyak produk pomade yang dipasaran masih menggunakan bahan-bahan kimia. Tentu hal ini mengacu pada terciptanya produk pomade CROT-DE dengan berbahan dasar alami dari lidah buaya. Selain harga yang terjangkau dari pomade CROT-DE ini, produk ini juga berbahan dasar alami yang aman digunakan oleh konsumen. Produk CROT-DE ini dapat digunakan oleh kalangan laki-laki remaja sampai dewasa. Analisis SWOT adalah metode perencanaan strategis yang terdiri dari aspek Strenght (kekuatan) produk, Weaknesses (kelemahan) produk, Opportunities (peluang) produk, dan Threats (ancaman) produk

Untuk lebih jelas hasil analisis SWOT dalam penelitian ini dapat dilihat dalam Tabel 1

\begin{tabular}{|c|c|c|}
\hline $\begin{array}{l}\text { Analisis } \\
\text { SWOT }\end{array}$ & $\begin{array}{l}\text { Strength }(\mathrm{S}) \text { Kekuatan } \\
\text { 1.Bahan baku yang mudah di } \\
\text { dapat } \\
\text { 2. Produk ini menggunakan } \\
\text { bahan-bahan alami } \\
\text { 3. Harga relatif terjangkau } \\
\text { 4. Produk pomade sangat disukai } \\
\text { pria dari kalangan remaja sampai } \\
\text { dewasa }\end{array}$ & $\begin{array}{l}\text { Weakness }(\mathrm{W}) \text { kelemahan } \\
\text { 1. Produk belum diketahui oleh } \\
\text { masyarakat } \\
\text { 2. Dampak terhadap yang } \\
\text { memiliki alergi terhadap tanaman } \\
\text { lidah buaya }\end{array}$ \\
\hline $\begin{array}{l}\text { Opportunities }(\mathrm{O}) \text { peluang } \\
\text { 1. Belum adanya produk pomade } \\
\text { berbahan dasar alami } \\
\text { 2. Produk dapat diperjual-belikan } \\
\text { melalui media online } \\
\text { 3. Dapat dipasarkan kepada } \\
\text { konsumen }\end{array}$ & $\begin{array}{l}\text { Strategi S-O } \\
\text { Dengan banyaknya produk } \\
\text { pomade dipasaran, hanya produk } \\
\text { pomade ini yang hanya } \\
\text { mengandung bahan alami. }\end{array}$ & $\begin{array}{l}\text { Strategi W-O } \\
\text { Melakukan pemasaran secara } \\
\text { efektif dapat dengan adversiting, } \\
\text { melalui media sosial, Instagram, } \\
\text { Whatsapp, dan Facebook dan } \\
\text { aplikasi belanja online seperti } \\
\text { Shoppe dan Tokopedia sehingga } \\
\text { dapat menarik minat para } \\
\text { konsumen dan mempermudah } \\
\text { konsumen untuk menjangkau } \\
\text { produk ini, mengingat orang- } \\
\text { orang sekarang lebih sering } \\
\text { belanja online karena lebih } \\
\text { praktis dan tidak menyita banyak } \\
\text { waktu seperti langsung pergi ke } \\
\text { toko-toko. }\end{array}$ \\
\hline
\end{tabular}


Muhammad Alvinza Chairyan, Ari Zulfi Kharisma, Muhammad Hanafi Lubis, Dhea Octa Yolanda, Suhelni

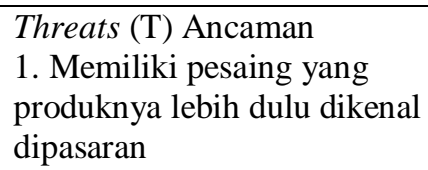

Threats (T) Ancaman 1. Memiliki pesaing yang produknya lebih dulu dikenal dipasaran

\author{
Strategi O-T \\ Harga yang ditetapkan sesuai \\ dengan keadaan konsumen dan \\ harga yang relatif terjangkau
}

\author{
Strategi W-T \\ Memperbaiki strategi-strategi \\ pemasaran dengan baik dan \\ bertahan pada pesaing usaha \\ diluar sana
}

Tabel 1 menghasilkan beberapa strategi dari analisis SWOT. Strategi-strategi tersebut dapat dilihat dari bagian berikut ini. Pertama adalah bagian Strategi SO. Strategi ini adalah mengembangkan produk pomade CROT-DE. Seperti yang telah kita ketahui, pomade yang telah beredar dipasaran menggunakan bahanbahan kimia yang dapat menimbulkan efek samping bagi rambut. Dengan banyaknya variasi dan manfaat dari produk ini, yakni dalam bentuk pomade yang menggunakan bahan-bahan alami dapat membuat kaum laki-laki tertarik kepada produk pomade ini. Strategi yang dapat dilakukan adalah produk ini satu-satunya pomade yang menggunakan bahan-bahan alami sehingga dapat bersaing dengan produk pomade lainnya yang telah beredar dipasaran dan telah dikenal oleh masyarakat banyak. Strategi ini sangat penting dan sangat utama dilakukan agar produk pomade CROT-DE dapat diminati oleh para kaum laki-laki.

Kedua adalah bagian Strategi OT. Strategi ini adalah yang memfokuskan kepada harga. Harga yang ditetapkan sesuai dengan keadaan konsumen dan harga yang relatif terjangkau yang akan dapat bersaing dengan harga produk lainnya yang ada dipasaran. Cara penetapan harga dapat ditentukan dari bahanbahan yang digunakan dan rumitnya cara pembuatan dari produk.

Ketiga adalah bagian Strategi WO. Strategi ini berpacu pada upaya melakukan pemasaran yang efektif dengan kegiatan periklanan. Periklanan dapat dilakukan dari media sosial, seperti Instagram, Whatsapp, Facebook atau media sosial lainnya. Dan juga melakukan pemasaran produk melalui aplikasiaplikasi belanja online seperti Shoppe, Tokopedia, dan sebagainya. Cara ini dapat menarik minat calon konsumen terhadap produk yang ditawarkan, mengingat orang-orang sekarang lebih sering berbelanja online karena keseharian mereka menggunakan gadget yang dimana gadget merupakan kebutuhan orangorang masa kini, lebih praktis dan tidak menyita banyak waktu seperti langsung pergi ke tokotoko. Adanya alternatif lain namun dapat membutuhkan biaya yang cukup besar, adalah menggunakan media massa koran sebagai media cetak pemasaran, dengan secara langsung, dan melalui kegiatan bazar atau expo produkproduk.

Keempat adalah bagian Strategi WT. Strategi keempat ini merupakan strategi yang digunakan untuk memperbaiki program pemasaran dengan strategi-strategi pemasaran yang baik dan memperbaiki berbagai kelemahan yang ada pada perusahaan untuk meminimalisir ancaman yang ada dan yang akan datang. Strategi ini memiliki tujuan agar bisnis mampu bersaing dengan produk-produk lainnya dipasaran dan agar mampu bertahan dalam persaingan dengan produk-produk yang sudah ada dipasaran.

\section{KESIMPULAN dan SARAN}

Pada penelitian ini telah dapat disimpulkan bahwa :

1.) Hasil dari analisis penelitian yang telah dilakukan adalah pada strategi kekuatan (strength) adalah bahan-bahan baku yang dibutuhkan dalam pembuatan produk pomade ini sangat mudah di dapat sehingga akan mempercepat proses produksi dan dapat segera dipasarkan sehingga dapat dijangkau oleh masyarakat.

2.) Produk ini menggunakan bahan-bahan alami sehingga aman bagi rambut/tidak menimbulkan efek samping bagi rambut.

3.) Pomade merupakan produk yang sangat disukai bahkan kebutuhan para pria dari kalangan remaja sampai dewasa.

4.) Hasil dari analisis penelitian yang telah dilakukan adalah pada strategi kelemahan (weakness) adalah produk pomade ini belum banyak diketahui oleh masyarakat.

5.) Hasil dari analisis yang telah dilakukan pada strategi peluang (opportuninities) adalah belum adanya produk pomade yang menggunakan bahan-bahan alami.

6.) Produk dapat diperjual-belikan melalui media online dan dapat dipasarkan langsung kepada konsumen.

7.) Hasil dari analisis yang telah dilakukan pada strategi ancaman (threats) adalah memiliki pesaing yang cukup berat yang produknya lebih dulu dikenal dipasaran dan sudah tersebar luas di berbagai daerah. 


\section{SARAN}

Pada penelitian ini terdapat saran bahwa :

1. Agar lebih memperbanyak refrensi sehingga lebih jelas.

2. Agar menggunakan kata-kata yang lebih mudah dipahami sehingga pembaca dapat lebih mudah memahami isi penelitian.

3. Tim CROT-DE harus mengembangkan inovasi pomade yang menggunakan bahanbahan alami ini mengingat belum ada pomade yang menggunakan bahan-bahan alami di pasaran.

4. Tim CROT-DE harus lebih meningkatkan proses pemasaran agar produk pomade ini dapat dikenal dan dijangkau oleh banyak masyarakat.

\section{DAFTAR PUSTAKA}

Gita. 2014. Sejarah Pomade. http://sashispomadeshop.blogspot.com/

Ayana. 2018. 7 Gaya Rambut Ini Populer Banget di Kalangan Cowok Lho.https://www.idntimes.com/men/groo ming/maria-liana/7-gaya-rambut-inipopuler-banget-di-kalangan-cowok-lhoc1c2/full

Angelica Tamara. 2016. Implementasi Analisis Swot Dalam Strategi Pemasaran Produk Mandiri Tabungan Bisnis. Jurnal Riset Bisnis dan Manajemen, 4(3), 395-406.

Istiqomah dan Irsad Andriyanto. 2017. Analisis SWOT dalam Pengembangan Bisnis (Studi pada Sentra Jenang di Desa Wisata Kaliputu Kudus). Jurnal Bisnis, 5(2).

Moeleong, Lexy J. 2014. Metodologi Penelitian Kualitatif. Bandung: PT. Remaja Rosdakarya.

Syamsudin Noor. 2014. Penerapan Analisis SWOT Dalam Menentukan Strategi Pemasaran Daihatsu Luxio Di Malang. Jurnal INTEKNA (2), $102-209$.

Tamara, A. 2016. Implementasi analisis SWOT dalam strategi pemasaran produk mandiri tabungan bisnis. Jurnal Riset dan Manajemen, 4(3), 395-406. 